\title{
GLACIARES ROCOSOS DEL SECTOR CENTRAL DE LA MONTAÑA CANTÁBRICA: INDICADORES PALEOAMBIENTALES
}

\author{
R. PELLITERO ${ }^{(1)^{*}}$, E. SERRANO ${ }^{(1)}$, J.J. GONZÁLEZ TRUEBA ${ }^{(2)}$ \\ ${ }^{1}$ Departamento de Geografía. Universidad de Valladolid (UVA) \\ ${ }^{2}$ Departamento de Geografía, Prehistoria y Arqueología. Universidad del País Vasco (UPV)
}

\begin{abstract}
RESUMEN. Los glaciares rocosos son considerados geoindicadores fiables de la existencia de permafrost, asociado a unas temperatura media anual por debajo de $-2^{\circ}$ C. Los glaciares rocosos y lóbulos protalud relictos son formas bien conservadas que nos permiten inferir el ambiente en que fueron activos. El presente artículo analiza la distribución y características de los 32 glaciares rocosos y 9 lóbulos protalud del área central de la Cordillera Cantábrica. A partir de la forma, orientación, altitud y situación morfoestratigráfica de los glaciares rocosos se establecen 5 fases morfogenéticas. Finalmente se propone una hipótesis cronológica y una aproximación paleoclimática para dichas fases.

Rock glaciers in the Central Cantabrian Mountains: palaeoenvironmental indicators
\end{abstract}

\begin{abstract}
Rock glaciers are considered reliable indicators of permafrost occurrence, developed in environments with average temperatures below $-2^{\circ} \mathrm{C}$. Relict rock glaciers and protalus lobes are well preserved landforms which permit us to deduce the environment in which they were active. This article analyzes the distribution and characteristics of 32 rock glaciers and 9 protalus lobes in the central part of Cordillera Cantábrica. Based on the shape, orientation, altitude and morphostratigraphy of rock glaciers we have established 5 different phases of rock glacier formation. Finally a chronological hypothesis is purposed, and a palaeoclimatic inference is suggested for each phase.
\end{abstract}

Palabras clave: glaciares rocosos relictos, ambientes periglaciares, fases criogenéticas, Montaña Cantábrica.

Key words: relict rock glaciers, periglacial environments, cryogenic phases, Cantabrian Mountains. 
* Correspondencia: Departamento de Geografía. Universidad de Valladolid (UVA). 47011-Valladolid E-mail: mon@geo.uva.es

\section{Introducción}

En montañas donde las huellas frías periglaciares indicadoras de condiciones ambientales son poco frecuentes por su inexistencia o deterioro, los glaciares rocosos relictos, generalmente bien conservados, constituyen un elemento clave para la reconstrucción paleoambiental y paleomorfoclimática. Por esta causa han proliferado los estudios de glaciares rocosos en todas las montañas del mundo desde los años 80 del s. XX. En la Península Ibérica, donde existen glaciares rocosos relictos en todas las cordilleras de mayor altitud (Pirineos, Cantábrica, Montañas Galaicas, Sistema Ibérico, Sistema Central y Sierra Nevada), se ha constituido un cuerpo de conocimiento no completado, sobre todo de inventario y caracterización.

Los glaciares rocosos relictos, tambien denominados fósiles, son formas de origen periglaciar que ya no funcionan como tales al carecer de hielo intersticial, que forma entre el 30 y el $50 \%$ de un glaciar rocoso activo (Barsch, 1996). La morfología se conserva una vez desaparecido el hielo, aunque se pierde el característico frente escarpado y la presencia de finos, y se deterioran los arcos y surcos del cuerpo central. Los cambios morfológicos, la colonización liquénica y la vegetación hacen que los glaciares rocosos relictos sean fáciles de reconocer a pesar de la amplia variedad de formas y tamaños.

Los glaciares rocosos son en su origen directamente dependientes del clima y han sido utilizados frecuentemente como indicadores paleomorfoclimáticos. Su atribución a un origen glaciar o periglaciar ha sido ampliamente discutida, aunque en la actualidad una mayoría de investigadores admite que existen ambos tipos genéticos (Giardino et al., 1987; Barsch, 1996; Clark et al. 1998; Whalley y Azzizi, 1994; Hamilton y Whalley, 1998; French, 2007; Harrison et al. 2008). En todos los casos son necesarias unas condiciones frías en el suelo, con presencia de permafrost, que propicien la conservación y segregación de hielo en los sedimentos, ya sean de origen glaciar o periglaciar.

Los glaciares rocosos activos han permitido determinar las condiciones ambientales precisas para su desarrollo, asociado a la existencia de permafrost de montaña. $\mathrm{Su}$ presencia se ha relacionado con temperaturas medias anuales (TMAA) menores de $-2^{\circ} \mathrm{C}$, en ambientes con permafrost discontinuo, si bien su génesis esta determinada por condiciones más frías, con TMAA más bajas de $-6^{\circ} \mathrm{C}$, en ambientes con permafrost continuo (Haeberli, 1985; King, 1986; Humlum, 1998). Por ello constituyen inmejorables indicadores de condiciones térmicas y ambientales, tanto del presente -indicadores de permafrost- como para el pasado -indicadores de medios periglaciares, de permafrost y de condiciones térmicas concretas. La presencia de glaciares rocosos está condicionada por factores ambientales y topoclimáticos, que pueden ser determinantes. Por ello, la presencia de un reducido numero de glaciares rocosos no constituyen buenos indicadores paleomorfoclimáticos, pero sí la presencia de dichas formas de manera generalizada en determinados macizos o áreas de montaña. 
Los glaciares rocosos se relacionan con climas fríos y secos, interpretación basada en la necesaria reducción de precipitaciones para que los glaciares desaparezcan, el cinturón periglaciar se amplíe y los glaciares rocosos sean dominantes. Condiciones de frío intenso y escasas precipitaciones implican el dominio de los procesos periglaciares y las formas resultantes se asocian a condiciones más secas que el glaciarismo. Sin embargo, aunque su génesis se asocie a periodos de sequedad relativa respecto a periodos glaciares anteriores, los glaciares rocosos se generan en medios de amplia variabilidad en las condiciones de humedad o precipitación, que pueden oscilar entre menos de 400 hasta $2500 \mathrm{~mm}$ anuales (Haeberli, 1985). En montaña oceánica las precipitaciones posibilitan glaciares que alcanzan cotas muy bajas, se introduzcan en el cinturón montano y reduzcan el cinturón periglaciar. Mientras, en montañas continentales con glaciares cobijados en altitud, el cinturón periglaciar es más extenso y los procesos periglaciares más intensos, permitiendo una mayor profusión de glaciares rocosos. Pero durante los periodos de retroceso de los glaciares, tanto en ambientes oceánicos como continentales, éstos son sustituidos por ambientes periglaciares con permafrost, procesos criogénicos o congelamientos estacionales del suelo. Además, un enfriamiento moderado no implica necesariamente el desarrollo de glaciares pero sí de formas periglaciares, de modo que las fases cataglaciares, los ambientes paraglaciares y pequeñas variaciones térmicas son favorables al desarrollo de glaciares rocosos. Hoy día existen glaciares rocoso activos tanto en ambientes secos y continentales o mediterráneos (Rocosas, Andes Centrales, Alpes Centrales y Orientales, Himalayas, Tien Shan), como en ambientes oceánicos (Svalbard, Escandinavia, Shetland del Sur, Alpes Neozelandeses). Si en diversas montañas de la península Ibérica se han atribuido a una sola fase (fase Tardiglaciar o de glaciares rocosos) de condiciones frías y secas (Serrat, 1979; Vilaplana, 1983; Soria y Soria, 1987; Gómez Ortiz et al. 2002), en los Alpes y los Pirineos se han constatado hasta cuatro periodos de formación desde el máximo glaciar a la Pequeña Edad del Hielo (Jordá, 1983; Serrano, 1996, 1998, Serrano y Agudo, 2004). La presencia de glaciares rocosos en todo tipo de ambientes morfoclimáticos posibilitan su utilización como indicadores paleoambientales y permiten reconstruir las condiciones periglaciares del Pleistoceno y Holoceno.

\section{Objetivos y metodología}

Los objetivos del trabajo son identificar, clasificar y definir los glaciares rocosos de la porción central de la Montaña Cantábrica, donde se localizan los macizos más elevados en ambiente oceánico (Picos de Europa, Peña Sagra) y de transición oceánicocontinental (Peña Prieta, Cebolleda, Alto Campoo), atribuyendo una edad relativa a los diferentes aparatos inventariados. El inventario, análisis espacial y cronológico tiene como objetivo realizar una aproximación a las condiciones paleomorfoclimáticas y paleoambientales en los distintos periodos identificados.

La metodología utilizada se basa en el inventario y clasificación de los glaciares rocosos relictos y los lóbulos protalud (protalus lobes). Estos últimos se consideran glaciares 
rocosos embrionarios (Barsch, 1996) y por tanto formados en los mismo ambientes que aquellos. Sin embargo su escaso desarrollo altitudinal no nos permite inferir un límite superior e inferior para el dominio periglaciar a partir de los mismos, por lo que sólo se ha tenido en cuenta la altitud de sus frentes. El análisis de ambas formas atiende a su morfología (anchura, longitud, estructuras superficiales), génesis (enlace con taludes o paredes, depósitos morrénicos o circos glaciares) y emplazamiento (altitud de frente y raíz, orientación, sustrato), datos básicos para una clasificación genética y morfológica (Barsch, 1996). El análisis morfoestratigráfico de cada glaciar rocoso y lóbulo protalud inventariado mediante su relación con morrenas y formas de erosión glaciar permite situarlos temporalmente. Se ha establecido una cronología relativa para cada glaciar rocoso inventariado conforme a la evolución glaciar establecida en esta porción de la Cordillera Cantábrica: un Máximo Glaciar Pleistoceno (1), con fase de expansión y fase de estabilidad; una fase de retroceso Finiglaciar (2) muy pulsadora; una fase de avance menor de circos (3), con morrenas alojadas en los circos, en altitud y que denotan al menos dos fases en Picos de Europa, correlacionada con los Alpes y Pirineos con el Tardiglaciar; y un último periodo glaciar histórico (4), de glaciares reducidos y alojados en los circos mas altos, perteneciente a la Pequeña Edad del Hielo (Serrano, 2001; Serrano y Gutiérrez, 2002; Serrano y González Trueba, 2002, 2005; González Trueba, 2006, 2007a y 2007b; González Trueba et al. 2008; Pellitero, 2008, 2009; González Trueba y Serrano, 2010).

Partiendo de que la altitud mínima de los frentes señalan el límite inferior del permafrost, que coincide con la isoterma de $\operatorname{los}-2^{\circ} \mathrm{C}$ de temperatura media anual del aire (TMAA), los glaciares rocosos y lóbulos protalud se utilizan como indicadores de cambios ambientales pasados (Kerschner, 1978; Haeberli, 1985; Barsch, 1996; Serrano, 1996; Frauenfelder y Kaab, 2000; Frauenfelder et al. 2001; Lambiel y Reynard, 2001; Dornbusch, 2005; Harrison et al. 2008). Mediante la estimación para cada periodo con glaciares rocosos de la isoterma de $-2^{\circ}$, se puede calcular la diferencia de temperatura entre cada periodo y respecto a la actualidad, asi como los cambios en el desarrollo altitudinal del ámbito periglaciar. La estimación de las temperaturas se ha realizado para 2000 y $2500 \mathrm{~m}$. En el primer caso se ha calculado a partir del gradiente derivado de la diferencia de nivel entre la raíz y los frentes, asignado $-2^{\circ} \mathrm{C}$ a los frentes y $-6^{\circ} \mathrm{C}$ a la raíz, con gradientes muy acusados. A su vez, a partir del límite inferior de los frentes glaciares se ha estimado con un gradiente teórico de $0,6^{\circ} \mathrm{C} / 100 \mathrm{~m}$. El promedio ha sido utilizado para estimar la diferencia de temperatura entre las distintas etapas. La raíz de los glaciares rocosos se relaciona con la existencia de permafrost continuo y TMAA menores de $-6^{\circ} \mathrm{C}$, parámetro que complementa la información sobre la intensidad de los procesos periglaciares. No se consideran los cambios sucedidos en la radiación solar, los gradientes locales, la nubosidad, ni el espesor y duración del manto nival, efectos parcialmente compensados por el número de glaciares rocosos analizados. Todo ello permite una aproximación a la distribución del permafrost, la extensión altitudinal del piso periglaciar y las diferencias térmicas en cada fase de desarrollo de glaciares rocosos. 


\section{Los glaciares rocosos en la Cordillera Cantábrica}

Clarck (1981) cita por primera vez la existencia de glaciares rocosos en la Cordillera Cantábrica y los atribuye al final de la fase glaciar "de montaña", coincidente con un ascenso de la línea de equilibrio glaciar y la instalación de condiciones periglaciares por encima de los 1900 metros en toda la Cordillera. Posteriormente se han descrito y estudiado estas formas a lo largo de la Cordillera Cantábrica, en Ancares y Degaña (Alonso, 1989; Pérez Alberti et al., 1994), Omañas y el Bierzo (García de Celis, 1991; Redondo et al. 2002, 2004), Montaña Central Leonesa (González Gutiérrez, 2000), Macizo Asturiano (Rodríguez, 1995; Jiménez, 1996), Alto Esla (Alonso Herrero, 2002), Picos de Europa (Serrano y González Trueba, 2004, 2005; González Trueba, 2007a, 2007 b), Alto Campoo (Serrano y Gutiérrez, 2000; Serrano, 2001), macizo de Peña Prieta-Curavacas (Frochoso y Castañón, 1996; Pellitero, 2008, 2009; Santos et al., 2009), y en el pico Orvillo, montaña cuarcítica al sur del Espigüete (Fernández Martínez y Fuertes, 2008).

Caben destacar dos características básicas de la distribución de los glaciares rocosos de la Montaña Cantábrica (Alonso, 1989; García de Celis, 1991; Redondo et al., 2004), por una parte la orientación septentrional de la mayoría de los glaciares rocosos, ubicados generalmente dentro de antiguos circos glaciares, lo que ayuda a su reconstrucción morfoestratigráfica, y por otra su preferencia por sustratos silíceos duros, en especial cuarcitas y, muy secundariamente, areniscas y conglomerados. Por el contrario los glaciares rocosos son escasos en los macizos calcáreos y pizarrosos.

En la Cordillera Cantábrica los glaciares rocosos se desarrollan bajo condiciones ambientales específicas, que impiden su ubicuidad, por lo que son especialmente interesantes para la reconstrucción morfoestratigráfica y paleoambiental. La mayoría de los estudiados han sido adscritos a la "fase de montaña" (Clark, 1981; Alonso, 1989; Alonso Herrero, 2002), datados por correlación con los Pirineos (Serrat 1979), en el Tardiglaciar. En este artículo se pretende mostrar que dichas formas, al igual que lo ocurrido en Pirineos y Alpes, se han originado durante distintas fases frías pleistocenas y holocenas.

\section{La zona de estudio}

La zona estudiada de la Cordillera Cantábrica (Fig. 1) comprende su porción central, entre $\operatorname{los} 5^{\circ} \mathrm{E}$ y $\operatorname{los} 4^{\circ} 22^{\prime} \mathrm{E}$. Incluye una sucesión de sierras y macizos entre los que se encuentran los mas elevados de la Cordillera, Picos de Europa (2650 m.) y Peña Prieta $(2539 \mathrm{~m})$. De norte a sur, se han analizado las montañas atlánticas de Picos de Europa (Cornión, Urriello y Andara) y Peña Sagra (Cornón, 2047 m.), las montañas de la Divisoria, Sierra de Cebolleda (Gildar, 2078), Sierra de Solvorón (Coriscao, 2234 m.), Peña Prieta y Sierra de Peña Labra-Cordel (Tres Mares, 2171 m.), y las sierras meridionales del Alto Carrión (Curavacas, 2524 m. Espigüete, $2451 \mathrm{~m}$.), Sierra de Hijar (Cuchillón, 2174 m.) y Sierra del Brezo (Peña del Fraile, 2001 m.). Todo el conjunto de sierras se encuentran en el límite occidental de la cobertera mesozoica (Peña Sagra y 


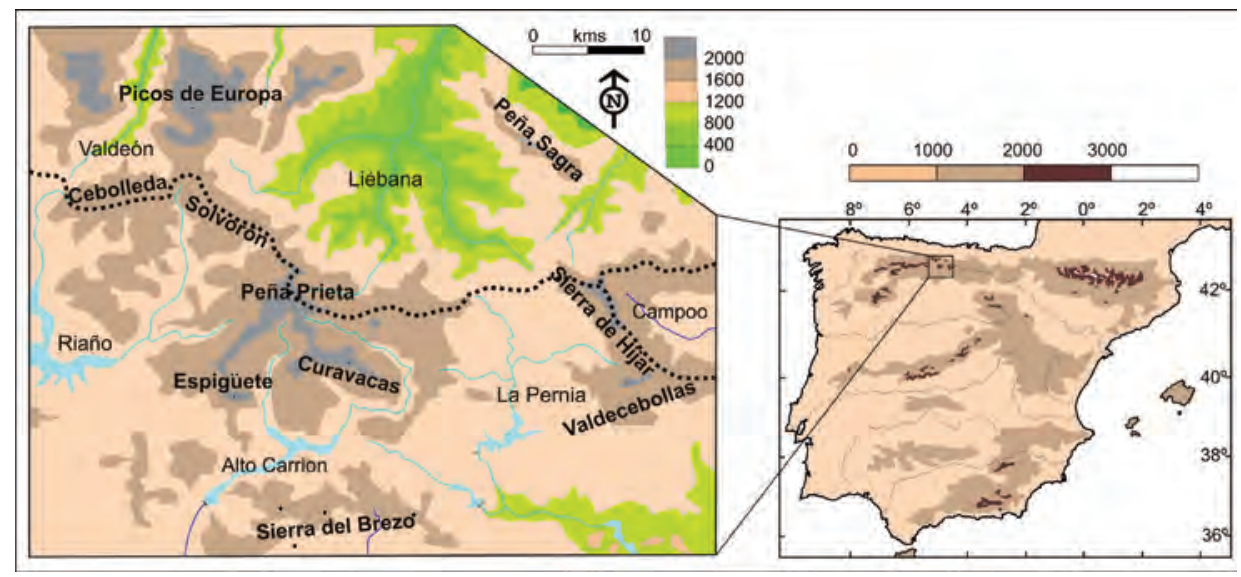

Figura 1: Localización de la Zona de estudio. Los topónimos señalan los macizos y Sierras estudiadas.

Alto Campoo) y en la porción oriental del Macizo Asturiano. Las primeras se articulan como cordales de altitudes moderadas (1900-2100 m.) constituidos por conglomerados y areniscas triásicos, y las restantes por las unidades cabalgantes en escamas y mantos que configuran sucesivos alineamientos de direcciones dominantes E-W, desde los Picos de Europa al norte hasta la Sierra del Brezo al sur.

Los Picos de Europa están formados por una sucesión de escamas cabalgantes de vergencia norte constituidas por calizas paleozoicas, compartimentados por profundas gargantas y limitados por depresiones (Sajambre, Valdeón y Liébana) caracterizados por los fuertes desniveles y un relieve complejo derivado del modelado glaciokárstico. Al sur se emplaza la divisora, constituida por sierras de menor altitud (Solvorón, Cebolleda), caracterizadas por la fuerte tectonización de los cabalgamientos y la diversidad litológica, donde se suceden calizas, areniscas, lutitas, conglomerados y pizarras paleozoicas. Se articulan como sierras de orografía simple y altitudes modestas, excepto en Peña Prieta, con fuertes disimetrías entre las vertientes septentrionales, más abruptas y encajadas, y las meridionales.

El Macizo de Peña Prieta y la Montaña Palentina constituyen un conjunto también muy heterogéneo, con una gran variedad litológica, y altitudes máximas que rondan los 2000 metros salvo para los grupos más elevados, que llegan a los 2500 metros. Se trata de un conjunto de pliegues cabalgantes de dirección general WNW-ESE sobre los que destacan el manto conglomerático-lutítico del Curavacas-Lechada, la intrusión granodiorítica de Peña Prieta y el cabalgamiento calizo del Espigüete. Los valles, vertientes a la red del Duero, son amplios y poco encajados, con depósitos aluviales colgados unos 100 metros por encima del nivel actual de base. Por último los glaciares cuaternarios han ejercido un retoque en los relieves previos, formando circos, valles en artesa y complejos morrénicos en todos los macizos, grupos y sierras estudiados. 
En este conjunto, localizado en su porción septentrional a una veintena de kilómetros del mar, se ubican dos ambientes diferenciados, una porción plenamente atlántica, al norte de la divisoria, con precipitaciones que superan los $2500 \mathrm{~mm}$ anuales en las montañas y una montaña de transición atlántico mediterránea, donde las precipitaciones se moderan, por debajo de los $1000 \mathrm{~mm}$ anuales, diferenciándose también por la moderada pero existente sequía estival. La isoterma de los $0^{\circ} \mathrm{C}$ se sitúa a $2500 \mathrm{~m}$ en los Picos de Europa (Muñoz, 1982; González Trueba, 2007) y en torno a los 2700 metros en el macizo del Curavacas (Pellitero, 2008).

\section{Los glaciares rocosos de la zona de estudio}

Se han inventariado y analizado 41 glaciares rocosos y lóbulos protalud dispersos por la zona de estudio (Tablas 1 y 2). La mayor parte (61\%) se localiza en la Montaña Palentina, en la porción de transición atlántico-mediterránea, y sólo 9 de ellos $(22 \%)$ en la montaña atlántica, mientras 7 (17\%) se sitúan en la Divisoria, donde las condiciones de oceanidad y su localización en vertientes septentrionales permiten aproximar las condiciones ambientales a las atlánticas. Este dominio de los glaciares rocosos en la vertiente meridional está sujeto a otros factores que los climáticos, pues se debe tener en cuenta aspectos como la baja altitud de algunas montañas atlánticas (Cordel, Peña Sagra), o el dominio calcáreo de los Picos de Europa. Por ello, es necesario analizar los factores que intervienen en la distribución de los glaciares rocosos de la Cordillera Cantábrica.

La orientación de los glaciares rocosos muestra una preferencia por el primer octante. De los 41 glaciares rocosos y lóbulos protalud, más de la mitad se orientan al N, NNE ó NE (Fig. 2). Las condiciones periglaciares necesarias para su formación, por encima de límite del permafrost discontinuo, dirigen esta organización, y sugieren que muchos de ellos se generaron cuando tanto la ELA como el límite inferior del permafrost discontinuo se situaban por encima del nivel de cumbres en las orientaciones desfavorables.

El análisis de la litología denota el control que ejerce sobre el desarrollo de los glaciares rocosos (Fig. 3). Estos se sitúan principalmente sobre rocas silíceas duras, tales como las cuarcitas, los conglomerados silíceos o las granodioritas. Estas litologías poseen una gran resistencia a la alteración química pero una gran debilidad ante los esfuerzos mecánicos, tales como los ejercidos por los procesos de hielo-deshielo. El resultado es que el aporte de clastos desde las paredes formadas por estas litologías es lo suficientemente abundante para alimentar los glaciares rocosos.

Por el contrario hay una casi completa ausencia de glaciares rocosos en macizos pizarrosos o calizos que, sin lugar a dudas, poseyeron un piso crionival en el Pleistoceno. Los escasos glaciares rocosos formados en calizas se asocian a líneas de falla y áreas de desprendimientos, donde la roca está naturalmente triturada. Por ello, si bien la existencia de glaciares rocosos es un geoindicador fiable de permafrost, su ausencia no 


\begin{tabular}{|c|c|c|c|c|c|c|c|c|c|c|c|c|c|c|c|c|}
\hline 总 & $\Xi$ & $\Xi$ & $\Xi$ & $\Xi$ & $\Xi$ & $\Xi$ & $\Xi$ & $\Xi$ & $\geq$ & $\Xi$ & ヨ & - & $\exists$ & $\exists$ & $\exists$ & $\exists$ \\
\hline 苟 & $\begin{array}{l}0 \\
0 \\
\frac{\pi}{\pi} \\
\tilde{\Xi} \\
0 \\
00 \\
\tilde{0} \\
0\end{array}$ & $\begin{array}{l}\tilde{o} \\
\tilde{\sigma} \\
\tilde{\Xi} \\
\tilde{\Xi} \\
\tilde{0} \\
\tilde{0} \\
\tilde{0} \\
\tilde{0}\end{array}$ & $\begin{array}{l}\stackrel{0}{0} \\
\stackrel{a}{\pi} \\
>\end{array}$ & 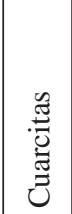 & 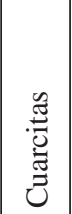 & 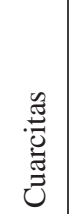 & 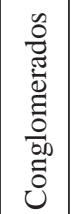 & 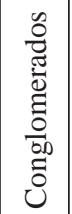 & 承 & 总 & 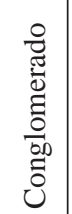 & 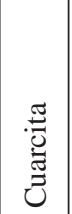 & 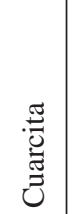 & 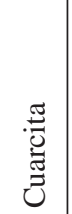 & 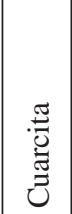 & 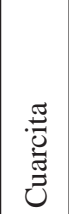 \\
\hline 苛 & Z & $\begin{array}{l}3 \\
\sqrt[n]{2}\end{array}$ & 山 & 峾 & 㞱 & 壱 & 文 & Z & Z & is & $\begin{array}{l}3 \\
0 \\
n\end{array}$ & Z & Z & 㞱 & 디 & 吾 \\
\hline 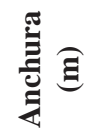 & $\stackrel{8}{\circ}$ & $\stackrel{\infty}{\varrho}$ & $\hat{n}$ & $\stackrel{\infty}{=}$ & 导 & $\stackrel{?}{\stackrel{\gamma}{\forall}}$ & ऽ & तี & $\underset{O}{O}$ & $\stackrel{8}{\circ}$ & જ & $\stackrel{\sim}{\sim}$ & $\underset{\infty}{\infty}$ & $\exists$ & 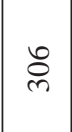 & हे \\
\hline$\stackrel{\dot{00}}{\stackrel{0}{\Theta}} \widehat{\Xi}$ & $\underset{⿱}{\mathbb{N}}$ & $\frac{?}{6}$ & $\stackrel{\infty}{\vec{\lambda}}$ & 点 & $\tilde{n}$ & $\stackrel{0}{\circ}$ & సે & $\stackrel{\widetilde{N}}{\mathrm{~N}}$ & $\hat{\sigma}$ & $\vec{b}$ & $n$ & $\underset{\infty}{\infty}$ & $\bar{a}$ & $\tilde{6}$ & గి & $\stackrel{\circ}{\circ}$ \\
\hline$\widehat{\Xi \Xi}$ & $\frac{\stackrel{P}{d}}{\sim}$ & 客 & હે & $\stackrel{?}{2}$ & $\frac{n}{\infty}$ & ণ্ণి & ळ & $\stackrel{\infty}{\infty}$ & $\stackrel{\text { I }}{\stackrel{\Delta}{\Delta}}$ & $\underset{\stackrel{0}{+}}{\stackrel{+}{\sim}}$ & ठิ & $\underset{\text { fo }}{\mathbb{Z}}$ & $\stackrel{?}{\stackrel{2}{I}}$ & $\stackrel{\curvearrowright}{\Xi}$ & $\underset{\infty}{\infty}$ & $\stackrel{\infty}{\Omega}$ \\
\hline 总 & $\hat{n}$ & ర్రి & $\stackrel{\Omega}{\Omega}$ & $\stackrel{2}{\varrho}$ & 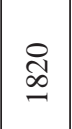 & $\begin{array}{l}\infty \\
\infty \\
\infty\end{array}$ & $\bar{\sigma}$ & 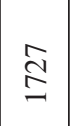 & 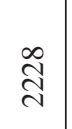 & $\begin{array}{l}\stackrel{0}{\sim} \\
\stackrel{+}{\sim}\end{array}$ & 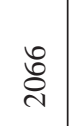 & 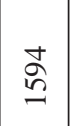 & $\underline{\Xi}$ & $\stackrel{\Xi}{\Xi}$ & $\stackrel{I}{I}$ & $\stackrel{n}{\varrho}$ \\
\hline ن் & 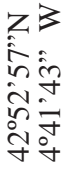 & 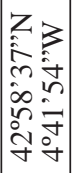 & 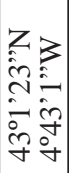 & 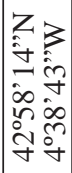 & 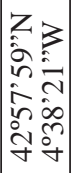 & 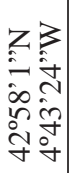 & 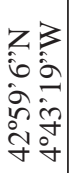 & 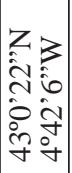 & 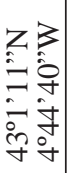 & 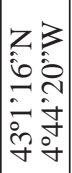 & 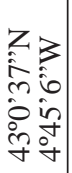 & 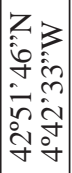 & 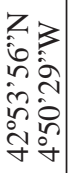 & 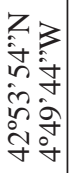 & 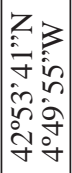 & 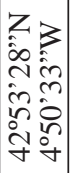 \\
\hline $\begin{array}{l}\text { है } \\
\text { है } \\
\text { Zे }\end{array}$ & $\frac{\stackrel{\Xi}{\Xi}}{\vec{\Xi}}$ & 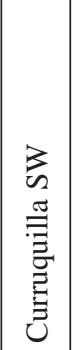 & 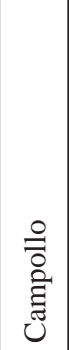 & 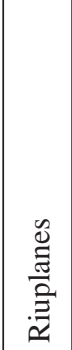 & 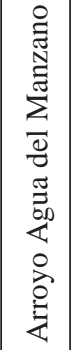 & 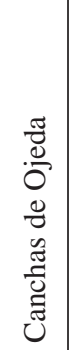 & 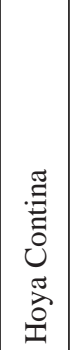 & 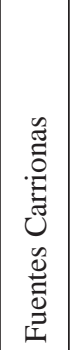 & 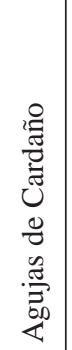 & $\begin{array}{c}3 \\
0 \\
0 \\
0 \\
0 \\
0 \\
.0 \\
0 \\
0 \\
0 \\
0 \\
0 \\
0 \\
0 \\
0\end{array}$ & 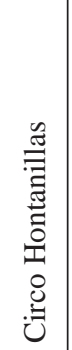 & 勇 & $\begin{array}{l}z \\
0 \\
= \\
0 \\
0\end{array}$ & 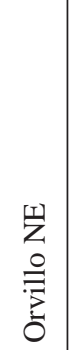 & 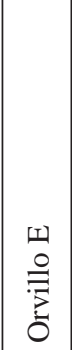 & \begin{tabular}{l} 
Iñ \\
0 \\
0 \\
\multirow{2}{0}{} \\
0
\end{tabular} \\
\hline$\frac{ \pm}{2}$ & \multicolumn{16}{|c|}{ 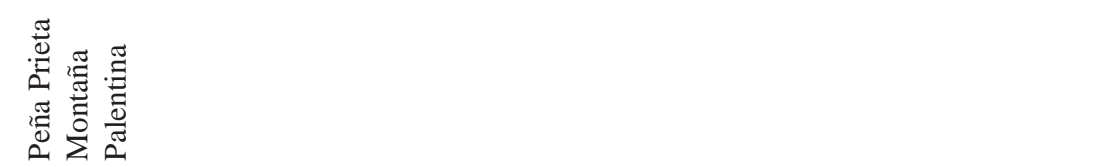 } \\
\hline
\end{tabular}




\begin{tabular}{|c|c|c|c|c|c|c|c|c|c|c|c|c|c|c|c|}
\hline$\geq$ & $\Xi$ & $\geq$ & $\exists$ & $\exists$ & $\exists$ & $\exists$ & $\exists$ & $\exists$ & 三 & $\exists$ & $\exists$ & $\exists$ & $=$ & $=$ & $=$ \\
\hline$\frac{\mathbb{N}}{\tilde{\mathcal{U}}}$ & 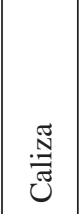 & : & 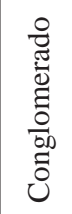 & $\begin{array}{l}\frac{o}{\tilde{\sigma}} \\
\overline{0} \\
\tilde{0} \\
0 \\
000 \\
0 \\
0\end{array}$ & 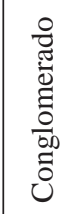 & $\begin{array}{l}\frac{0}{0} \\
\bar{\Xi} \\
\tilde{\Xi} \\
0 \\
00 \\
\overline{0} \\
0\end{array}$ & 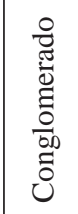 & 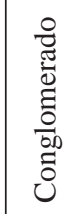 & 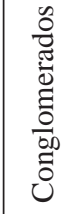 & 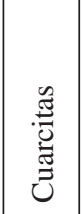 & 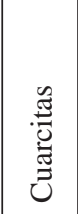 & 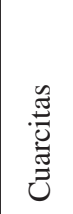 & 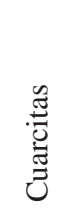 & 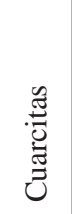 & 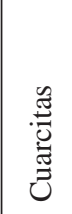 \\
\hline $\begin{array}{l}3 \\
n \\
n\end{array}$ & 3 & $\sim$ & Z & 岀 & 崩 & $\sum_{\text {工工工 }}^{\mid 山}$ & 㞱 & $\mathrm{Z}$ & Z & $\sum_{3}^{3}$ & 㞱 & 吕 & $\sqrt[T]{2}$ & Z & 之 \\
\hline 으 & 离 & $\stackrel{\circ}{n}$ & i & 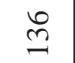 & $\stackrel{n}{\simeq}$ & $\stackrel{R}{2}$ & $\stackrel{\infty}{n}$ & $\widetilde{\sigma}$ & $\frac{n}{\sim}$ & 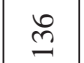 & $\widetilde{\sigma}$ & $\underset{\text { }}{\text { ర }}$ & ฉి & ণิ & $\stackrel{゚}{\curvearrowleft}$ \\
\hline$\underset{\overbrace{}}{\stackrel{1}{ }}$ & 尺 & 品 & $\stackrel{\text { है }}{\text { en }}$ & ণ্ণ & $\sqrt[n]{n}$ & $\hat{n}$ & $\stackrel{\infty}{-}$ & $\underline{6}$ & సి & $\stackrel{\overbrace{}}{\text { ¿े }}$ & $\stackrel{n}{n}$ & $\stackrel{n}{n}$ & $\stackrel{n}{2}$ & ஜூ & ঐิ \\
\hline ڤి & $\stackrel{n}{5}$ & $\begin{array}{l}\mathscr{n} \\
\stackrel{\infty}{i}\end{array}$ & 웅 & 음 & ̊으 & $\begin{array}{l}\infty \\
\infty \\
\infty\end{array}$ & శ్రి & $\stackrel{2}{\stackrel{2}{I}}$ & ஜ & $\underset{\infty}{\infty}$ & $\underset{\infty}{\&}$ & $\begin{array}{l}\stackrel{n}{n} \\
\infty\end{array}$ & $\stackrel{\text { \& }}{I}$ & $\stackrel{\infty}{\infty}$ & ๙ু \\
\hline$\stackrel{\wp}{\infty}$ & $\stackrel{\wp}{\curvearrowleft}$ & $\stackrel{2}{2}$ & ஜ̊ & 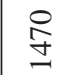 & 气ิ & 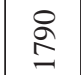 & $\underset{n}{\stackrel{2}{n}}$ & ్ㅡ & ஓ & $\stackrel{\infty}{\stackrel{\infty}{I}}$ & $\underset{0}{\infty}$ & $\begin{array}{l}\text { 尺 } \\
\text { ஜn }\end{array}$ & \&్ర & ఏ్రి & 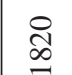 \\
\hline 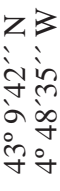 & 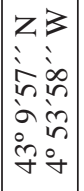 & 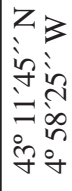 & 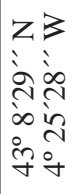 & 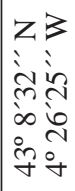 & 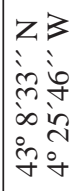 & 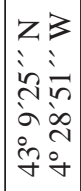 & 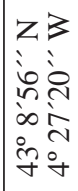 & 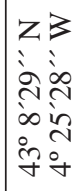 & 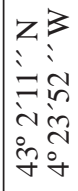 & 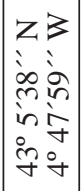 & 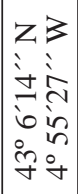 & 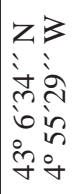 & 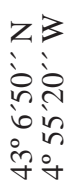 & 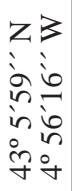 & 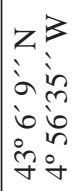 \\
\hline 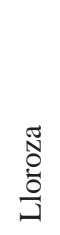 & 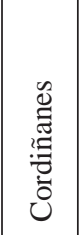 & 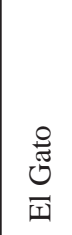 & 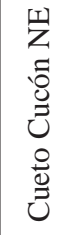 & 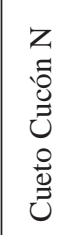 & 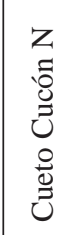 & 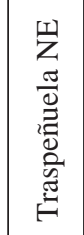 & 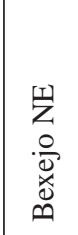 & 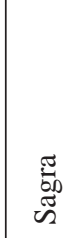 & $\frac{0}{\stackrel{0}{0}}$ & 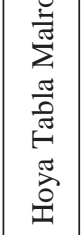 & 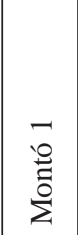 & 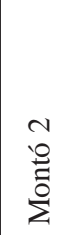 & 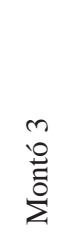 & $\begin{array}{l}\frac{0}{0} \\
\tilde{U} \\
\tilde{J} \\
\tilde{J} \\
\tilde{J} \\
\tilde{0} \\
\end{array}$ & 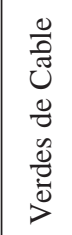 \\
\hline & 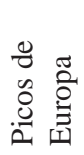 & & \multicolumn{6}{|c|}{ 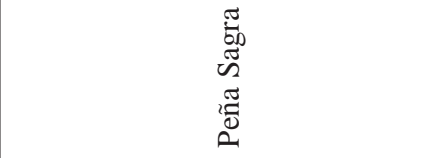 } & 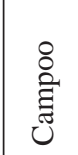 & 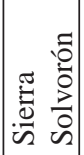 & \multicolumn{5}{|c|}{$\begin{array}{l}\frac{\pi}{0} \\
\frac{\pi}{0} \\
\stackrel{0}{0} \\
\stackrel{0}{0}\end{array}$} \\
\hline
\end{tabular}




\begin{tabular}{|c|c|c|c|c|c|c|c|c|c|}
\hline 焉 & 曰 & 日 & 目 & $\Xi$ & $Z$ & & $\geq$ & $>$ & $>$ \\
\hline 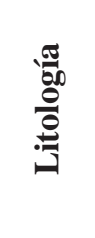 & 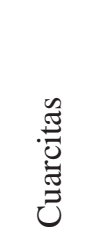 & 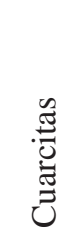 & 芯 & $\begin{array}{l}\frac{0}{0} \\
\frac{\pi}{0} \\
\tilde{0} \\
0 \\
000 \\
0 \\
0\end{array}$ & $\begin{array}{l}\frac{?}{0} \\
\frac{\pi}{0} \\
\tilde{0} \\
000 \\
0 \\
0 \\
0\end{array}$ & 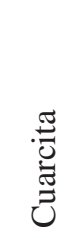 & 莺 & 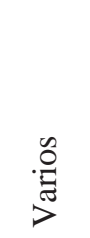 & 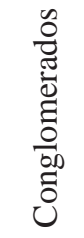 \\
\hline 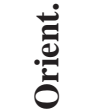 & 文 & is & 㞱 & in & Z & Z & Z & Z & Z \\
\hline$\underset{Z}{\stackrel{\Xi}{\Xi}} \widehat{\Xi}$ & 三 & ลิ & ర0 & $\stackrel{\sim}{\sim}$ & $\infty$ & $\stackrel{\varrho}{=}$ & $\infty$ & $\stackrel{\infty}{=}$ & ర్ర \\
\hline 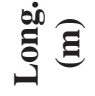 & ก & in & $\tilde{b}$ & $\stackrel{n}{f}$ & $\stackrel{\nabla}{\sim}$ & $\stackrel{n}{n}$ & $\stackrel{?}{\forall}$ & $\bar{\sim}$ & $\bar{n}$ \\
\hline ఏ્ઞ & $\stackrel{1}{\sigma}$ & 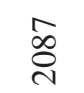 & مิ & ลิ & กิ & $\underline{\Xi}$ & $\stackrel{\vec{N}}{\Delta}$ & $\stackrel{n}{n}$ & તิ \\
\hline 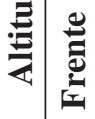 & ڤొ & ֻे & 6 & $\overrightarrow{\widetilde{N}}$ & $\stackrel{\text { I }}{\stackrel{\overbrace{}}{2}}$ & ô & $\begin{array}{l}\stackrel{n}{n} \\
\text { ה }\end{array}$ & $\stackrel{\infty}{\sim}$ & ঐิ \\
\hline ن் & 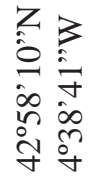 & 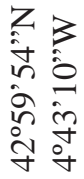 & 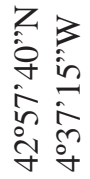 & 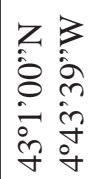 & 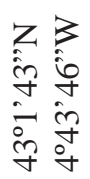 & 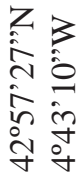 & 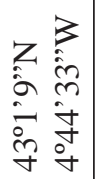 & 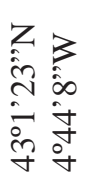 & 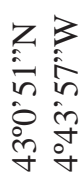 \\
\hline 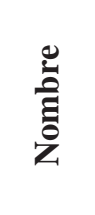 & 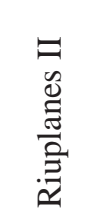 & 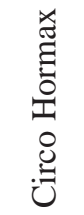 & 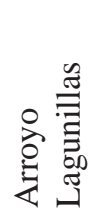 & 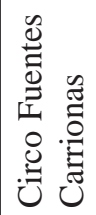 & 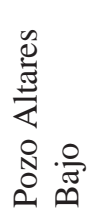 & $\begin{array}{l}\frac{n}{0} \\
\frac{0}{2} \\
\frac{0}{0} \\
\frac{\pi}{\pi} \\
>\end{array}$ & 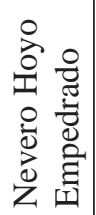 & 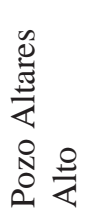 & 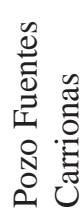 \\
\hline 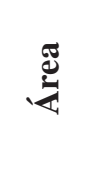 & \multicolumn{9}{|c|}{ 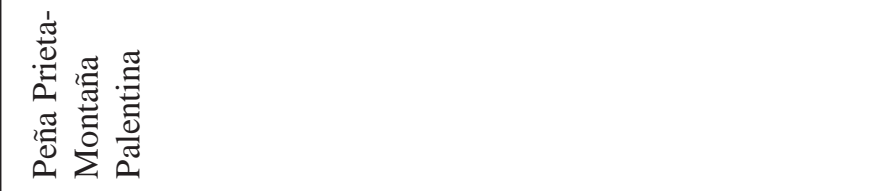 } \\
\hline
\end{tabular}




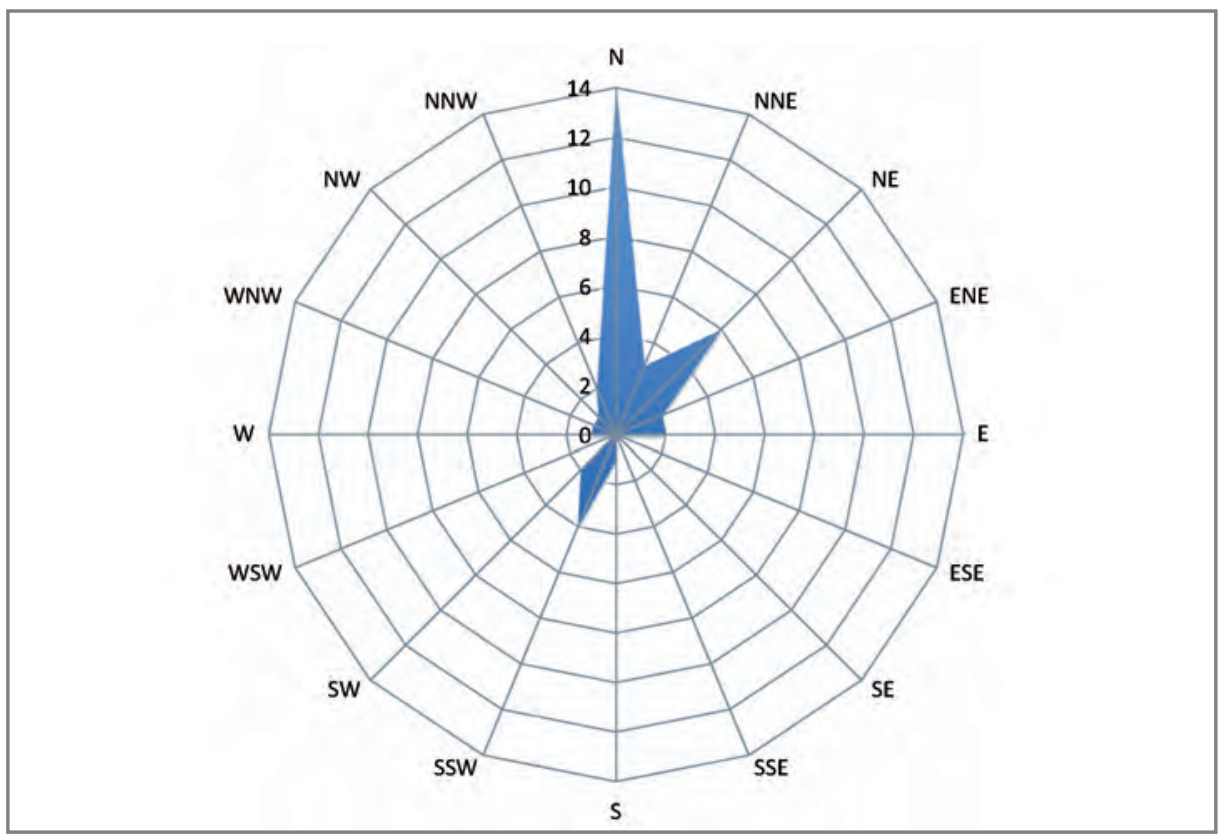

Figura 2: Distribución de las orientaciones de glaciares rocosos y lóbulos protalud.

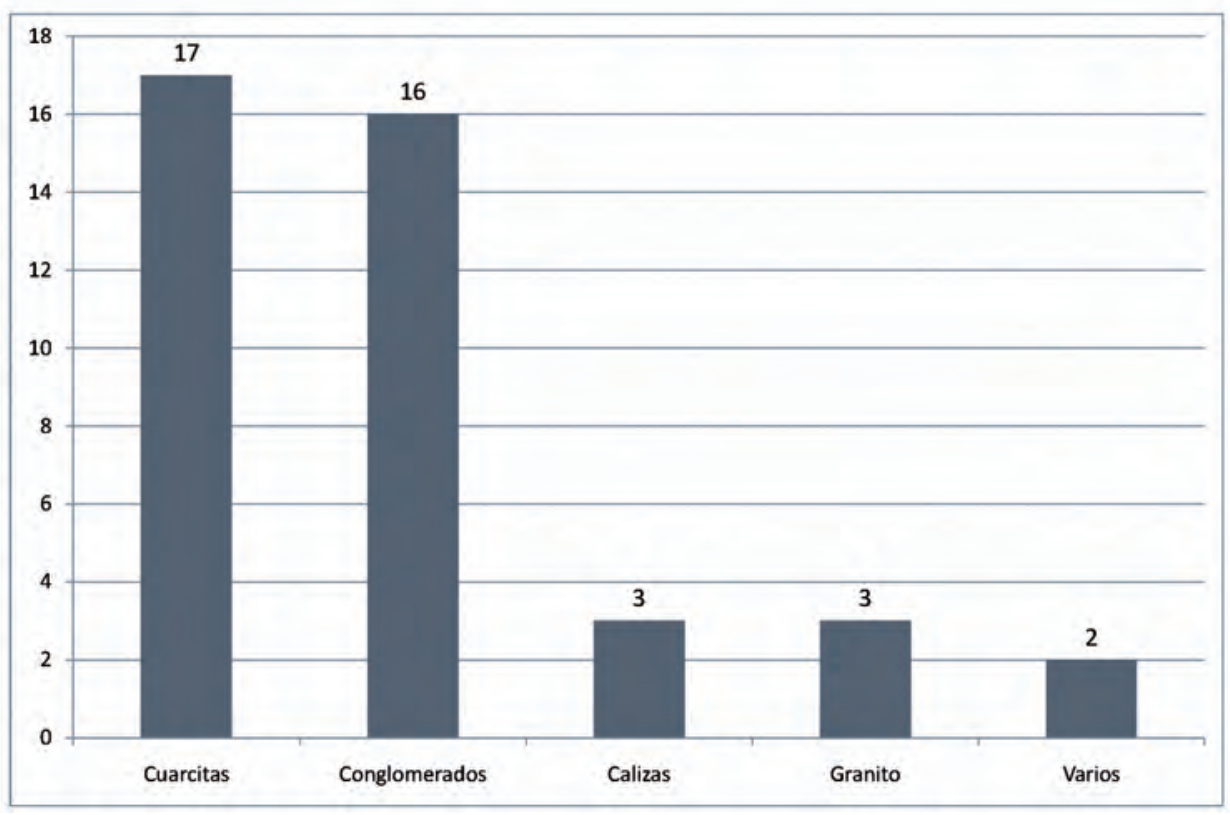

Figura 3: Distribución litológica de glaciares rocosos y lóbulos protalud. 

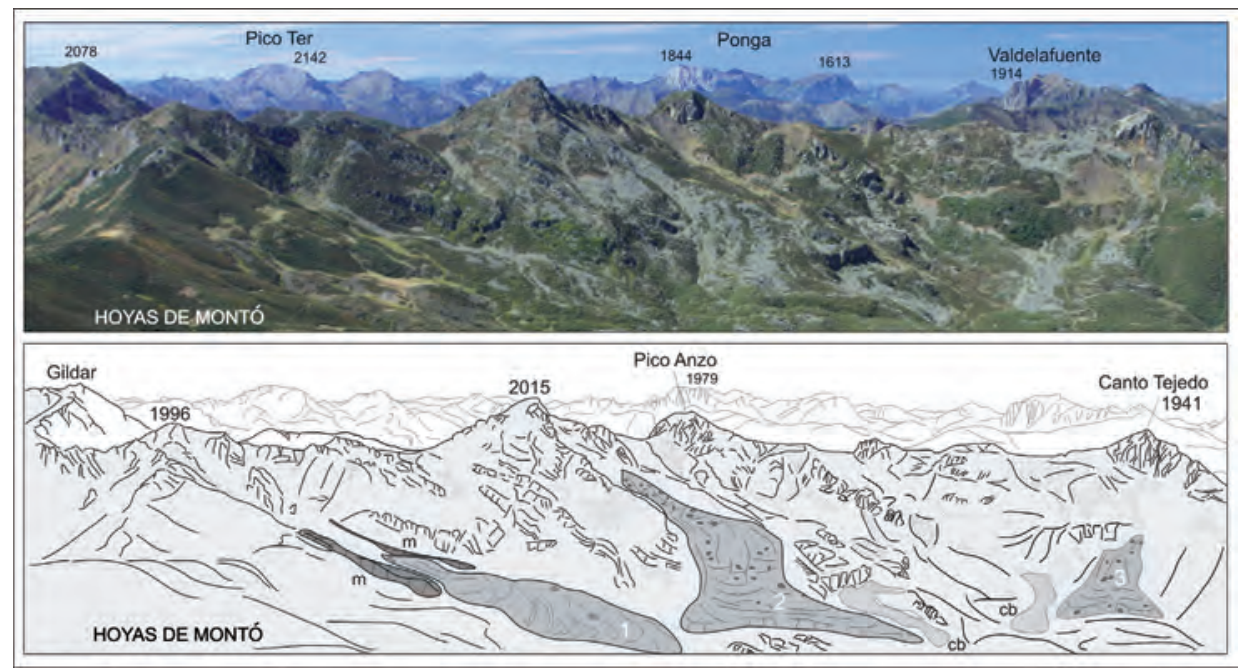

Figura 4: Hoyas de Montó, en la Sierra de Cebollera, desde el Pico Gabanceda. 1, 2 y 3: glaciares rocosos de Montó I, II y III; m: morrenas; cb: corrientes de bloques.

puede interpretarse como la ausencia de las condiciones climáticas para su formación. En ese caso habrá que atender a otro tipo de formas periglaciares activas o relictas.

Los glaciares rocosos del área de estudio poseen tamaños muy variados (Tablas 1 y 2), desde los 775 metros del más extenso, el de Curruquilla N, hasta los 20 metros del más pequeño, el lóbulo protalud del Pozo de los Altares Alto. Dicho rango posibilita la existencia de una gran variedad de formas. Encontramos grandes glaciares rocosos de tipo lengua, típicamente ubicados en el fondo de circos y artesas glaciares, con varias crestas y surcos intermedios, como el citado de Curruquilla, los situados en la cara $\mathrm{N}$ de la sierra de Cebollera (Fig. 4) o los de Orvillo E y SE.

Existen también glaciares rocosos lobulados, en los que no se ha desarrollado una lengua propiamente dicha, sino una pequeña cantidad de arcos que indican un flujo limitado. Éstos se sitúan en laderas con taludes de derrubios, y ocupan parcialmente circos y artesas glaciares. De este tipo son los glaciares de Peña Sagra, de los Asnos en Campoo, de Hoya Contina y Agujas de Cardaño en la Montaña Palentina o de Lloroza en Picos de Europa (Fig. 5). A esta tipología también responden los glaciares glaciogenéticos de Canchas de Ojeda y Campollo, aunque en este caso su raíz se encuentra en una morrena. Por último los lóbulos protalud, considerados como glaciares rocosos embrionarios, indican un flujo del cuerpo helado muy limitado.

La tendencia de los glaciares rocosos del área de estudio a ubicarse en relación con depósitos glaciares apoya un origen glaciogenético de la mayoría de ellos. Este hecho en las islas británicas ha sido interpretado por los condicionantes litológicos, poco favorables a la producción de clastos (Harrison et al. 2008), y en la necesidad de aportes 


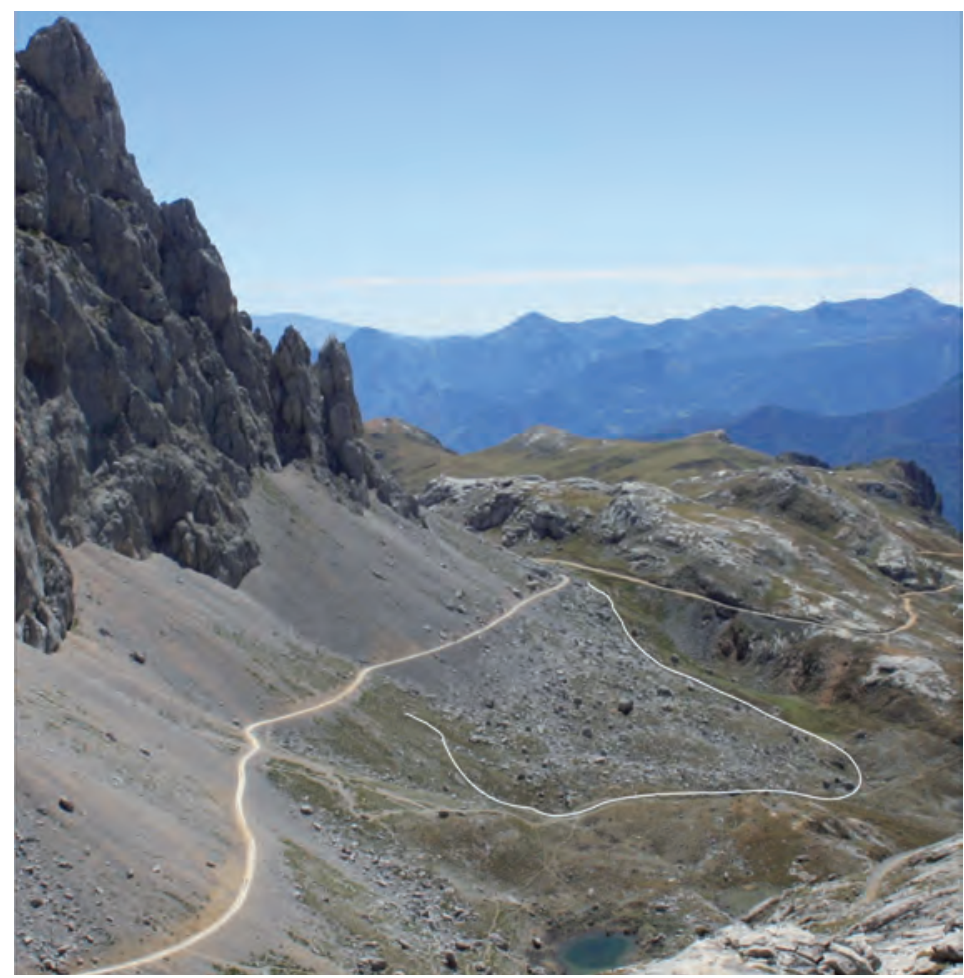

Figura 5: Glaciar rocoso de Lloroza, alimentado por un talud de derrubios al pie de Peña Olvidada. La línea blanca señala su límite lateral y frontal.

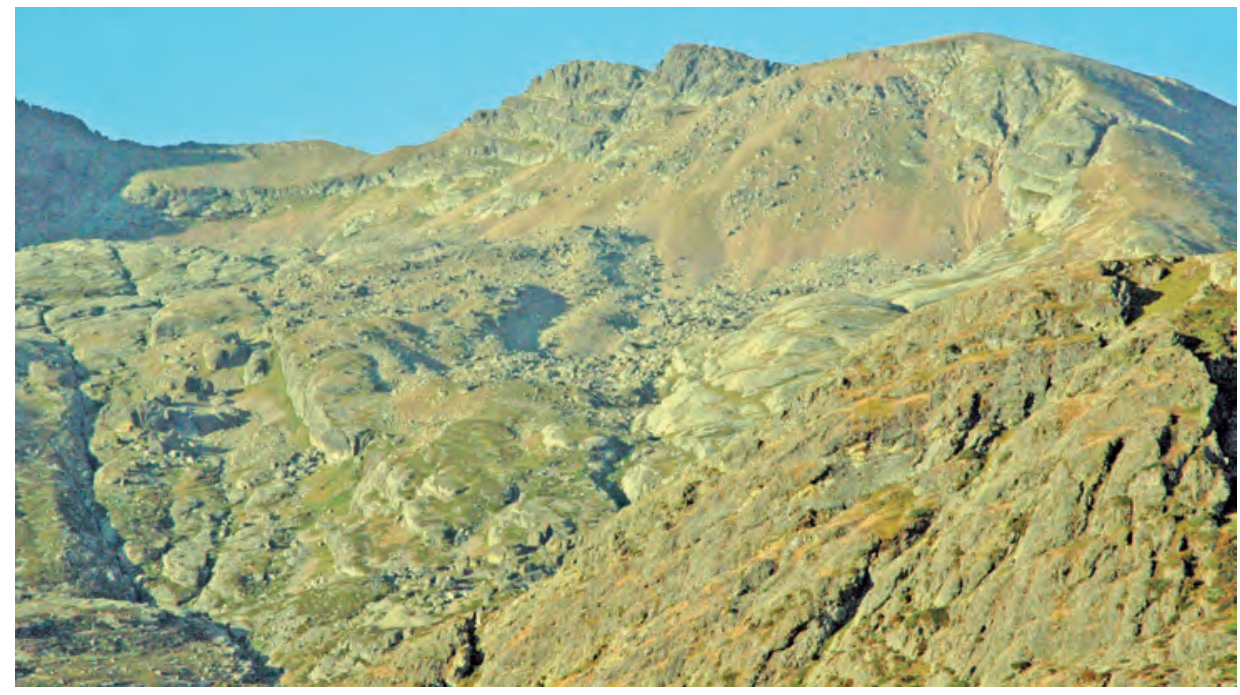

Figura 6: Glaciar rocoso de Curruquilla N, construido a partir de material morrénico y derrubios provenientes de los taludes del Pico Curruquilla durante la F. III. Foto de Alipio J. García de Celis. 
de derrubios, bien sea desde paredes o desde materiales previamente trabajados por el glaciar (Fig. 6). Si climáticamente parece lógico que existieran glaciares rocosos en orientaciones sur, coetáneos de glaciares ubicados en las orientaciones norte, en estos emplazamientos se desarrollaron sobre sustrato cuarcítico campos y corrientes de bloques (Pellitero, 2009), en los pizarrosos vertientes regularizadas con suelos más o menos desarrollados y en los calizos potentes acumulaciones de derrubios en ocasiones cementados, como las gonfolitas de Picos de Europa o los del Pico Espigüete o el Pico Santa Lucía. Las excepciones son los glaciares rocosos de Cordiñanes, Valdenievas y Tres Provincias, originados con aportes desde paredes no glaciadas. Tales excepciones apoyan el origen periglaciar de los glaciares rocosos, pero también la hipótesis sobre la formación de glaciares rocosos a favor de los aportes de clastos desde las paredes de los circos y artesas deglaciados por su verticalidad, desprotección edáfica, orientación favorable y los procesos paraglaciares consecuentes a la retirada de los glaciares (Ballantyne, 2002), en especial la fusión del permafrost y el desequilibrio morfodinámico generado en las paredes.

\section{Fases de formación de los glaciares rocosos}

La correlación morfoestratigráfica entre depósitos morrénicos, formas de erosión glaciar y los glaciares rocosos permite distinguir cinco fases de formación de glaciares rocosos con diferente distribución altitudinal de sus límites superiores e inferiores (Tabla 3).

- F. I: Una fase inicial, con glaciares situados fuera de los ámbitos glaciados, por lo que se sitúa en el Último Máximo Glaciar. Existen tres glaciares rocosos atribuidos a esta fase. Durante este periodo la ELA regional se situaba, en el caso de los Picos de Europa, alrededor de los 1600 metros (González Trueba, 2007) y en el macizo del Curavacas alrededor de los 1700 metros (Pellitero, 2008). Los datos relativos a la distribución de los límites altitudinales han de tomarse como referentes a situaciones especiales. En concreto en caras $\mathrm{N}$ el glaciarismo se extendía hasta cotas muchos más bajas que los 1644 metros en todos los macizos con picos por encima de los 2000 metros, y en la cara $\mathrm{S}$ de algunos macizos, como en el valle de Cardaño. Sin embargo la Sierra del Brezo, al abrigo de los frentes del N y NW, posee un desarrollo glaciar marginal. El glaciar rocoso de la Curruquilla $S$ se sitúa por encima de la ELA, hecho que explicamos por su ubicación en un topoclima especialmente hostil al glaciarismo, en cara SW, muy expuesto tanto a la insolación como a la deflación de la nieve, y por tanto no es útil como indicador paleoclimático. Por último el glaciar rocoso de Cordiñanes es una excepción a la regla, ya que se encuentra en una orientación particularmente desfavorable, en calizas (aunque alimentado por un cantil muy fracturado por la tectonización previa de una falla) y en un entorno sin glaciación previa. Dicho glaciar rocoso nos indican la existencia de permafrost rondando los 1000 metros en los Picos de Europa. 


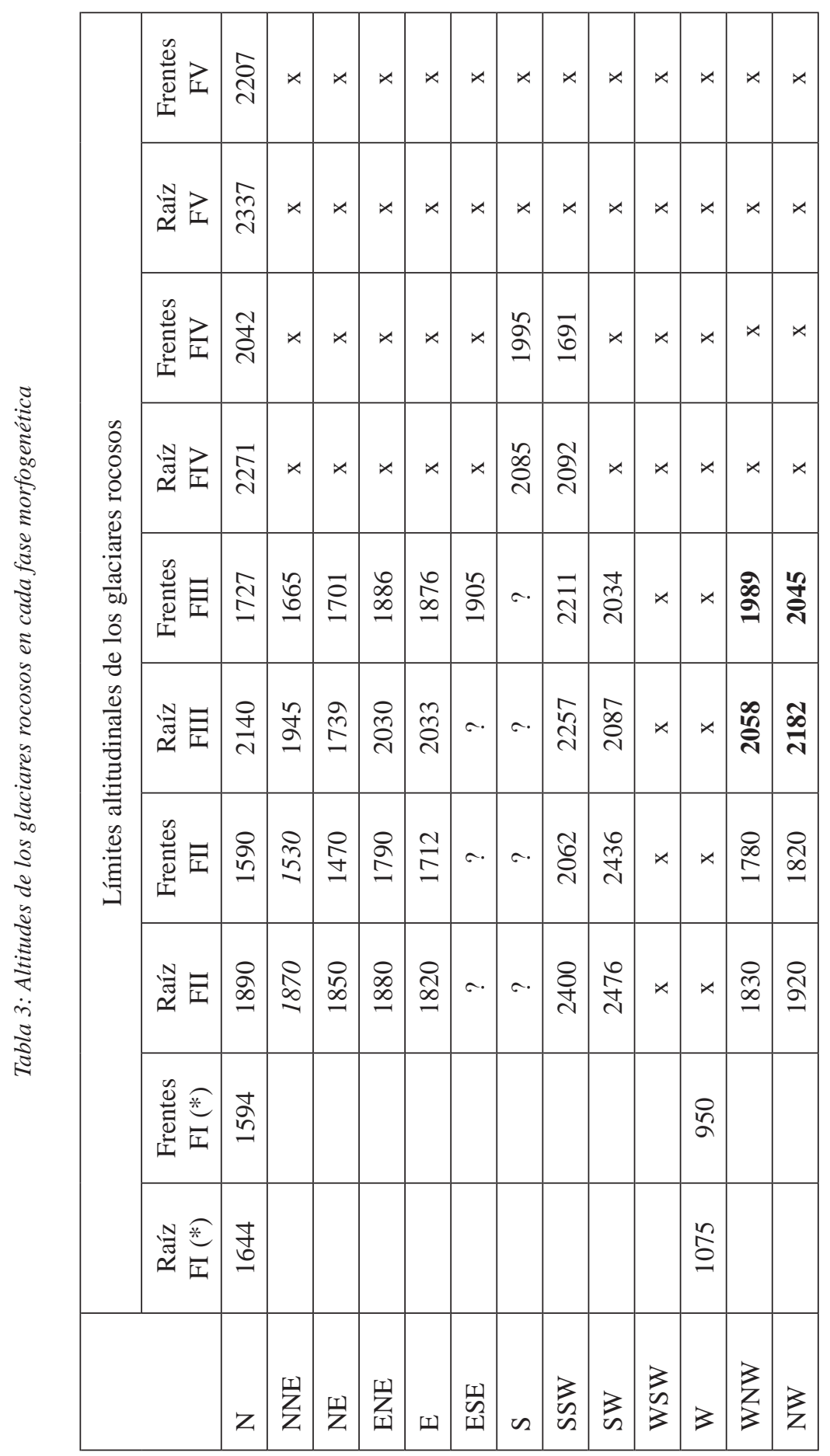

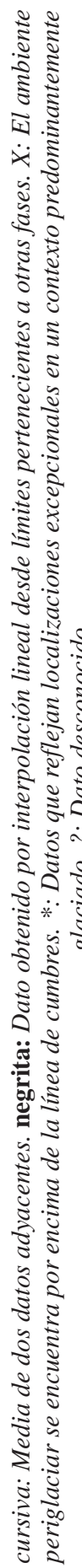


- F. II: Es la segunda más representada dentro del área de estudio, a ella pertenecen el $35 \%$ de los glaciares rocosos estudiados. Coincide con una fase de equilibrio glaciar en el interior de los valles y circos glaciares muy bien representada en la Cordillera Cantábrica, perteneciente a una fase posterior a la deglaciación de los valles principales, que asociamos al periodo Finiglaciar. El $73 \%$ de glaciares rocosos adscritos a esta fase se orientan entre el $\mathrm{N}$ y el E. Sin embargo existen glaciares rocosos en casi todas las orientaciones, lo que nos permite establecer que la altitud de las raíces de los mismos se situaría alrededor de los 1500 metros en las orientaciones septentrionales ( $\mathrm{N}$ a NE), para ascender hasta los 1700-1800 metros en las meridionales. Los glaciares rocosos son en general de gran tamaño, con varios cientos de metros de longitud y formas lobuladas o de lengua, lo que indica un piso crionival amplio y un extenso periodo criogenético.

- F. III: Asociados a una fase de equilibrio glaciar alojada en los circos, con morrenas de altitud, se desarrollan 12 glaciares rocosos y 6 lóbulos protalud. Esta fase criogenética se correlaciona con el Tardiglaciar, fase a la que en muchos trabajos han asociado los glaciares rocosos cantábricos (Alonso, 1989; García de Celis, 1991; Pérez Alberti et al., 1994; Rodríguez, 1995; Jiménez, 1996; Alonso Herrero, 2002; Redondo et al. 2002, 2004; Pellitero, 2008). Es la fase más representada (16 formas), y las orientaciones son mucho mas variadas que en la fase anterior, tanto para los glaciares rocosos como para los lóbulos protalud, aunque sigue habiendo una preferencia por los circos con orientaciones entre N y E (60\%). La deglaciación generalizada deja espacio libre para la instalación de glaciares rocosos en los circos más altos, ocupados por glaciares durante el Finiglaciar (Fig. 6). Esto solamente es posible en un ambiente suficientemente frío para la creación de un dominio crionival pero suficientemente seco como para impedir el avance glaciar. Por tanto la distribución de glaciares rocosos en el área central de la Cordillera Cantábrica confirma un ambiente menos frío y menos húmedo que el Finiglaciar, con un incremento del frío sin incremento de humedad con respecto al interglacial previo, capaz de generar pequeños glaciares y un amplio dominio periglacia. El piso crionival se situaría por encima de los 1700 en orientaciones septentrionales, 1850 metros en las orientales, donde todavía existen generalmente glaciares por encima de este límite, 2200 en las meridionales y $2100 \mathrm{~m}$ en las occidentales. En estos dos últimos casos el límite superior se encontraría, de forma general, por encima de la línea de cumbres en la mayoría de los macizos estudiados, al encontrarse las caras $\mathrm{S}$ y $\mathrm{W}$ mayoritariamente deglaciadas.

- F. IV: En los circos glaciares más altos y en orientaciones septentrionales del sector de Peña Prieta se encuentran glaciares rocosos de moderadas dimensiones, posteriores a la deglaciación Tardiglaciar, que señalan un periglaciarismo marginal, acantonado en los enclaves más favorables. Todos ellos se encuentran en lugares glaciados durante el Tardiglaciar, al interior de las morrenas glaciares de dicha fase. El glaciar rocoso de Agujas de Cardaño y el protalus lobe de Hoyo Empedrado se sitúan en el circo de Hoyo Empedrado, entre los 2270 y 2220 metros de altitud en el interior de una morrena glaciar, orientados al norte, protegidos y alimentados por las paredes granodioríticas de las Agujas de Cardaño, donde los procesos de gelifracción son todavía activos. El segundo ha sido interpretado como una morrena de nevero (Santos et al., 2009), pero 
parece probable la influencia del permafrost en su formación por su tamaño y la posición de los clastos que la forman, e incluso por la localización posible de permafrost en la actualidad (Santos et al., 2009). El lóbulo protalud de Pozo Altares Bajo se encuentra sobre una morrena del Tardiglaciar, a 2050 metros de altitud. Se alimenta directamente de la pared N de Peña Prieta, en la que los procesos de gelifracción, caída de bloques y derrumbes han sido muy activos. Esta cuarta fase por tanto denota un dominio periglaciar presente únicamente en las caras N por encima de los 2050 - 2100 metros, aun conviviendo con la existencia de dos pequeños glaciares de circo en Fuentes Carrionas y Pozo de los Altares. En los Picos de Europa existen dos glaciares rocosos relacionados con un periodo último de la fase Tardiglaciar, alojados al interior de las morrenas atribuidas a este periodo, y con orientaciones meridionales. Su génesis se asocia posiblemente a la desaparición del hielo y la descongelación de las paredes con sobrealimentación de clastos, al tiempo que perduran las condiciones de permafrost en el fondo de los circos, congelando y movilizando los derrubios en un ambiente paraglaciar. Dichos glaciares rocosos indican condiciones periglaciares mucho más rigurosas para los Picos de Europa que para el resto de macizos durante la misma fase.

- F. V: Los lóbulos protalud del Pozo Fuentes Carrionas (Fig. 7) y Pozo de los Altares Alto se encuentran al interior de las morrenas adscritas a la fase anterior, también en orientación septentrional. Son formas netas, adyacentes a neveros permanentes y morrenas de nevero activas actualmente, de muy pequeño tamaño (con frentes de menos de 10 metros de altura), testigos de una fase caracterizada por un piso crionival muy marginal, acantonado en orientaciones $\mathrm{N}$ en los pocos rellanos existentes por encima de los 2200 metros de altitud, en un entorno ya completamente deglaciado. Su situación se sitúa, por tanto, en el Holoceno.

\section{El medio periglaciar de montaña durante el Cuaternario}

La distribución de glaciares rocosos señala la existencia de un medio periglaciar entre los 900 y 2500 metros durante el Pleistoceno y el Holoceno. Durante la fase de máxima expansión el ámbito periglaciar, con posible permafrost desde los 1000-1500 metros, es reducido, pues los glaciares son dominantes en los valles. En este periodo los frentes glaciares alcanzan los 900 metros en Liébana, los 1000 en Valdeón, los 1470 en el Esla y entre 1280 y 1380 en la Montaña Palentina.

Durante las sucesivas fases de génesis de los glaciares rocosos se aprecia un descenso del desarrollo altitudinal por el ascenso del límite inferior de los frentes, moderado en las fases II y III, y más brusco durante las fases IV y V (Fig. 7). Este paulatino acortamiento altitudinal se acompaña de una menor disimetría entre orientaciones entre las fases II y III (Fig. 8). La fase II se caracteriza por la disimetría (340 metros entre las orientaciones $\mathrm{N} \mathrm{y} \mathrm{S}$ ), con moderadas diferencias altitudinales entre los límites de los frentes y las raíces, muy próximos en las orientaciones desfavorables. El periglaciarismo intenso se desarrolló desde los 1870 metros en las orientaciones N y los 2060 en las meridionales, y el límite inferior del permafrost se situó a 1530 metros en las orientaciones 


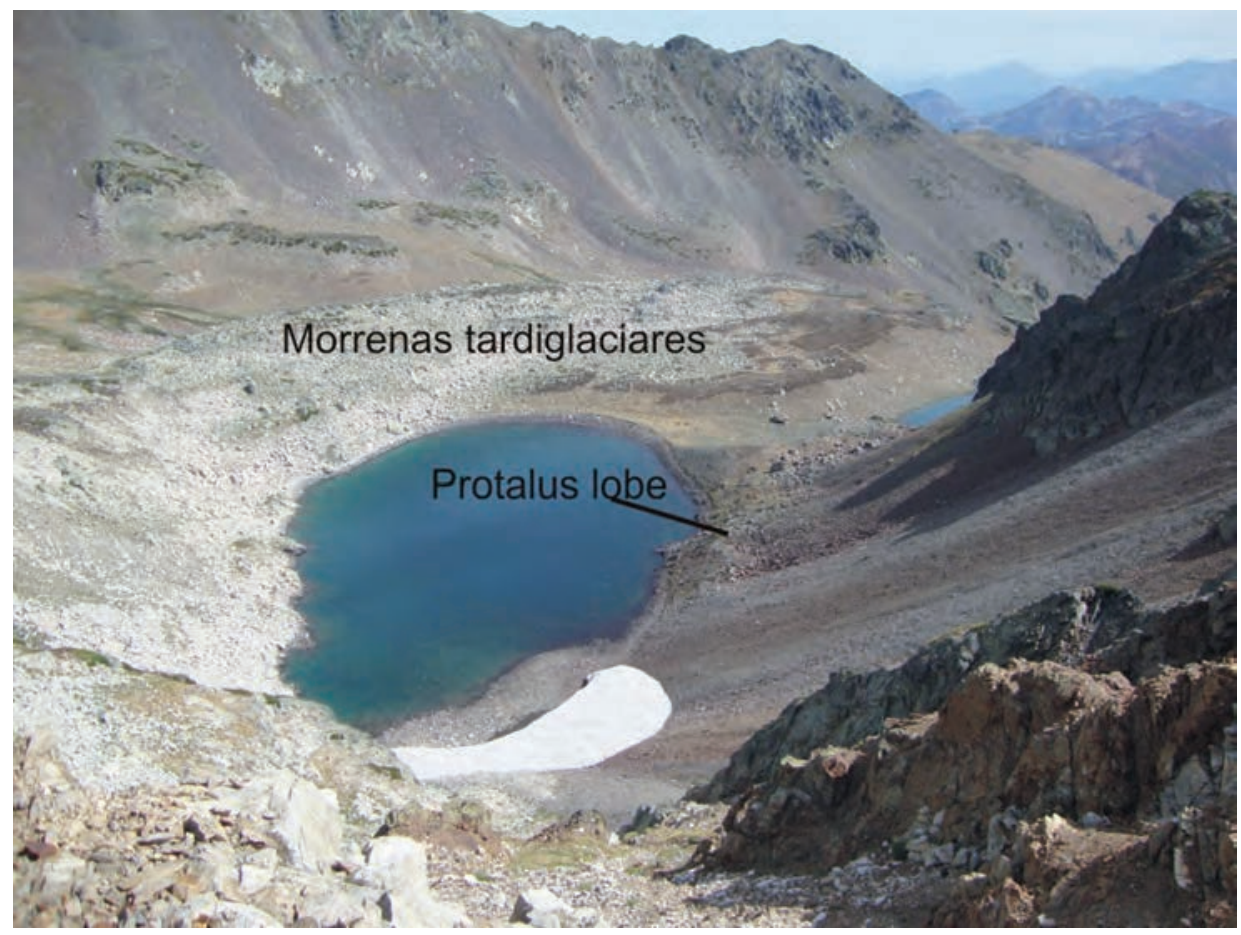

Figura 7: Lóbulos protalud del Pozo de Fuentes Carrionas, emplazado tras la deglaciación tardiglaciar.

septentrionales y 1970 en las meridionales. Aunque ocupa un amplio gradiente altitudinal de la montaña, una gran parte de los circos y valles más altos estaban ocupados por glaciares, por lo que el cinturón periglaciar quedaba limitado en extensión a las laderas y circos libres de hielo.

En la fase III, se produce un ascenso del límite superior de glaciares rocosos sobre todo en las vertientes norte, más moderado en las meridionales, de modo que el piso crionival posee mayor desarrollo vertical entre la altitud de los frentes y de las raíces de los glaciares rocosos tanto en las orientaciones $\mathrm{N}$ como $\mathrm{S}$. Se trata de un ascenso del piso periglaciar, pero al tiempo se hace más extenso, con menor dependencia de los factores topoclimáticos. Los glaciares ya han desaparecido en su mayor parte, y el periglaciarismo alcanza un amplio desarrollo en todas las orientaciones. Las diferencias térmicas estimadas respecto a la fase anterior son moderadas, de $+0,8^{\circ} \mathrm{C}$ para las orientaciones septentrionales. Todo ello denota un periodo caracterizados por frío intenso, similar al periodo anterior, pero con un descenso de la humedad que posibilita la desaparición de los glaciares y la persistencia de procesos periglaciares. El permafrost está presente desde los $1700 \mathrm{~m}$ en orientaciones septentrionales y los 2100 en las meridionales, con un periglaciarismo intenso, asociado a un posible permafrost continuo desde los 1940 metros 


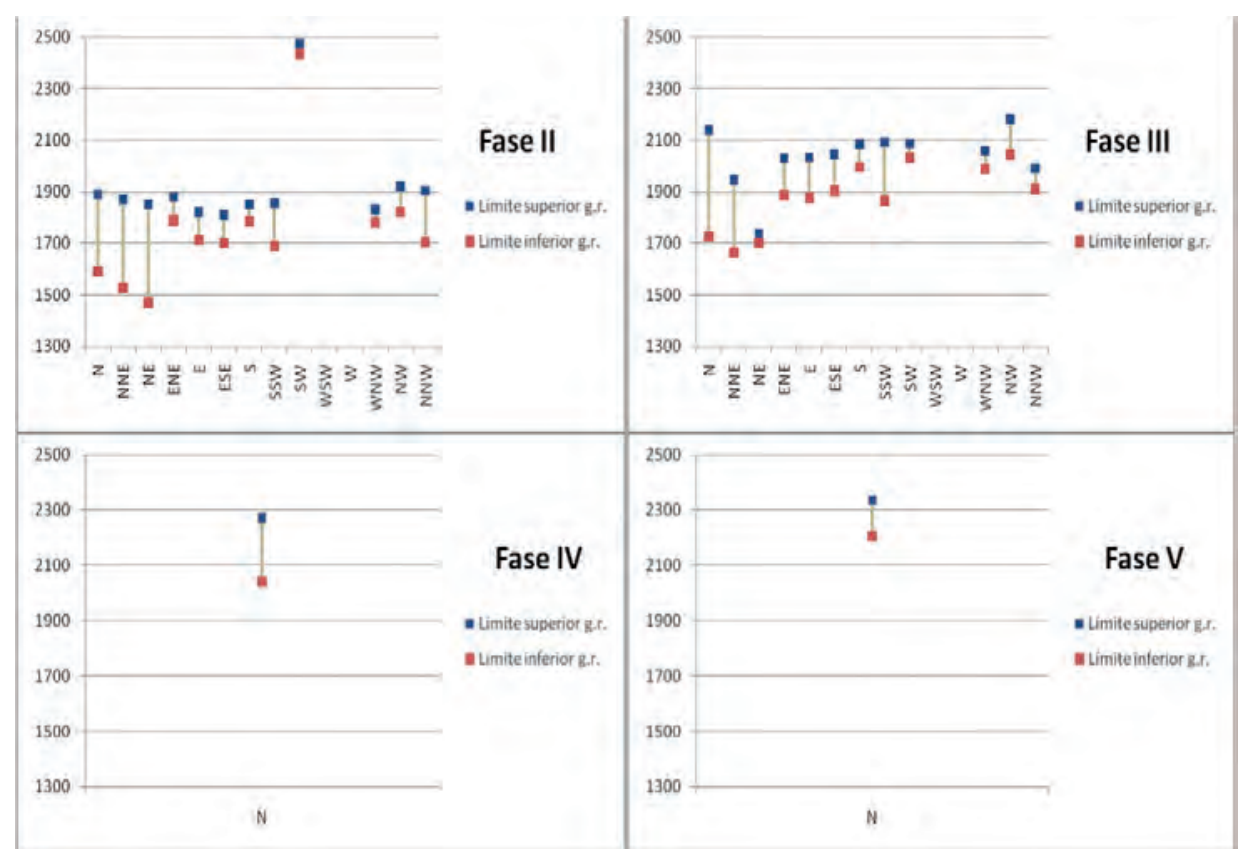

Figura 8: Límite superior e inferior (en m s.n.m.) y desarrollo vertical de los glaciares rocosos y lóbulos protalud del área de estudio para las fases II, III, IV y V.

en orientaciones septentrionales y los 2200 en las meridionales, es decir circunscrito a los cordales más elevados y las cumbres.

Las fases IV y V señalan ya dominios periglaciares dominados por los factores topoclimáticos, con los glaciares rocosos adscritos exclusivamente a las orientaciones septentrionales, por lo que las disimetrías son muy fuertes. Al sur no existirán ambientes con permafrost, que se acantonan en las orientaciones septentrionales. En la fase IV las temperaturas a $2000 \mathrm{~m}$ ascienden $3^{\circ} \mathrm{C}$ respecto a la fase anterior, y el permafrost se emplaza por encima de los 2040 metros, con un desarrollo vertical en torno a $450 \mathrm{~m}$. La ubicación será en las paredes y laderas de los circos glaciares orientados al norte, donde las dinámicas paraglaciares favorecerán la génesis de glaciares rocosos. La fase $\mathrm{V}$ es ya un periodo de periglaciarismo marginal, condicionado por los factores topoclimáticos, asociado a los recuencos más protegidos de las caras norte, y con permafrost por encima de $2210 \mathrm{~m}$. Los procesos periglaciares más intensos se desarrollan por encima de los 2340 metros, ya en la zona alta de los circos y laderas. En este periodo la temperatura asciende $1,3^{\circ} \mathrm{C}$ respecto a la fase anterior. El permafrost será esporádico y estará cobijado en las umbrías.

A partir de las estimaciones térmicas se puede establecer que para la fase II, correlacionada con el Finiglaciar Pleistoceno, las temperaturas descendieron respecto a la 
actualidad un promedio de $9,8^{\circ} \mathrm{C}$ (entre 9,6 y $10^{\circ} \mathrm{C}$ ) a 2000 metros de altitud. Estas temperaturas son acordes con las estimaciones recientes en Europa o las Rocosas (Brugger, 2006; Allen et al. 2008). Para la fase II, el descenso térmico estimado es de $6,8^{\circ} \mathrm{C}$ y para la Fase III de $6,6^{\circ} \mathrm{C}$ (entre 5,8 y $7^{\circ} \mathrm{C}$ ). Estos datos señalan la proximidad ambiental entre estas fases, con unas temperaturas similares, si bien la primera glaciada y la segunda deglaciada, ambas asociadas a la glaciación de altura, en el Tardiglaciar. Existen estimaciones muy diversas sobre las temperaturas del Tardiglaciar en Europa, con descensos estimados para los Alpes de $3^{\circ} \mathrm{C}$ y para los Pirineos de $6^{\circ} \mathrm{C}$, estas últimas cercanas a las estimadas en la Cantábrica, si bien el margen de error es amplio. Finalmente, el descenso térmico de la fase $\mathrm{V}$ no es significativo por el amplio margen de error y por la escasa representatividad de los espacios con glaciares rocosos.

\section{Conclusiones}

Los 41 glaciares rocosos estudiados han mostrado una amplia heterogeneidad morfológica y diversidad de tamaños, génesis y emplazamientos. Dominan los glaciares ubicados dentro de áreas previamente glaciadas y se ha detectado una marcada preferencia por las orientaciones septentrionales (N, NNE y NE). La litología es un factor determinante en la distribución de los glaciares rocosos, emplazados dominantemente sobre rocas silíceas duras, cuarcitas, conglomerados silíceos y granodioritas. De este modo se confirma para la porción central de la Montaña Cantábrica el hecho generalizado en toda la cordillera de la dominante septentrional y la preferencia litológica.

Por el contrario, los glaciares rocosos de este sector se han adscrito a cinco fases morfogenéticas diferenciadas, sin predominio neto de una fase de génesis de glaciares rocosos. Estas fases han mostrado un paulatino acortamiento altitudinal del permafrost hasta quedar acantonado en los circos glaciares, mostrando cada una de ellas una diferente distribución altitudinal y características ambientales. Una fase inicial (F. I) se define por su carácter glaciar, con un número reducido de glaciares rocosos, que situamos en el Último Máximo Glaciar. La segunda fase (F. II) generó glaciares rocosos ubicados ya en altitud y se relaciona con un periodo de equilibrio glaciar Finipleistoceno. El mayor desarrollo del permafrost se genera durante la fase III, periodo caracterizado por el ambiente frío y más seco que el periodo precedente. Finalmente, un periodo menor (F. IV), pero de condiciones térmicas muy similares, desarrolló los glaciares rocosos asociados a la movilización de los derrubios en ambientes paraglaciares. Tanto la fase III como la IV las situamos en el Tardiglaciar. Las dos últimas fases, F. IV y F. V se definen por la dependencia de los factores topoclimáticos y su adscripción exclusiva a orientaciones septentrionales con un dominio del permafrost discontinuo y esporádico. La última la atribuimos al Holoceno.

La reconstrucción de paleoambientes de montaña mediante el análisis de los glaciares rocosos ha permitido una primera aproximación a los ambientes periglaciares, si bien es necesario avanzar en el conocimiento cronológico mediante dataciones absolutas 
que permitan confirmar las correlaciones propuestas. Al mismo tiempo, la reconstrucción paleoambiental se puede completar con análisis complementarios relativos a los glaciares y su evolución (estimaciones de paleoELA y reconstrucción climática) y los depósitos lacustres (palinología) para precisar las condiciones ambientales y la evolución periglaciar en las montañas centrales cantábricas.

\section{Agradecimientos}

Este trabajo ha sido financiado por el Programa de Investigación del Ministerio de Ciencia e Innovación, proyecto CGL-2010-19729, por el Ministerio de Medio Ambiente, proyecto OAPN-053/2010 y por el programa FPU del Ministerio de Educación.

\section{Referencias bibliográficas}

Allen, R., Siegert, M.J., PAyne, A.J., (2008). Reconstructing glacier-based climates of LGM Europe and Russia-Part 2: A dataset of LGM precipitation/ temperature relations derived from degree-day modelling of palaeo glaciers. Climate of the Past, 4: 249-263.

Alonso Herrero, E., (2002). El glaciarismo en las cuencas altas de los ríos Esla y Porma. En: El modelado de origen glaciar en las montañas leonesas (Redondo, J.M., Gómez, A., González, R.B., Carrera, P., Eds.), Universidad de León, pp. 235-248, León.

Alonso, V., (1989). Glaciares rocosos fósiles en el área Degaña-Leitariegos (occidente de Asturias Cordillera Cantábrica). Cuaternario y Geomorfología, 3 (1-4): 9-15.

Ballantyne, C.K., (2002). Paraglacial geomorphology. Quaternary Science Review, 21: 1935-2017.

BARSCH, D., (1996). Rock Glaciers. Indicators for the Present and Former Geoecology in High Mountain Environment. Springer Verlag, Heidelberg.

BRUGGER, K.A., (2006). Late Pleistocene climate inferred from the reconstruction of the Taylor River glacier complex, southern Sawatch Range, Colorado. Geomorphology, 75, (3-4): 318-329.

Clark, R., (1981). Cold climate features of the Cordillera Cantábrica, northern Spain. Biuletin Peryglaciar, 28: 5-13.

Clark, D.H., Steig, E.J., Potter, N., Gillespie, A.R., (1998). Genetic variability of rock glaciers. Geografiska Annaler, 80: 175-182. 
DORNBUSCH, U., (2005). Glacier-rock glacier relationships as climatic indicators during the late Quaternary in the Cordillera Ampato, Western Cordillera of southern Peru. En: Cryospheric Systems: Glaciers and Permafrost (Harris, C., Murton, J. B., Eds), Geological Society, Special Publications 242, pp. 75-82, Londres.

Fernández MARTínez, E., Fuertes, I., (Coord.) (2008). Inventario de Lugares de Interés Geológico de la Provincia de Palencia. Consejería de Medio Ambiente de la Junta de Castilla y León, Valladolid. CD-ROM.

FRAUENFELDER, R., KÄÄB, A., (2000). Towards a palaeoclimatic model of rock-glacier formation in the Swiss Alps. Annals of Glaciology, 31: 281-286.

Frauenfelder, R., Haeberli, W., Hoelzle, M., Maisch, M., (2001). Using relict rockglaciers in GIS-based modelling to reconstruct Younger Dryas permafrost distribution patterns in the Err-Julier area, Swiss Alps. Norwegian Journal of Geography, 55: 195-202.

FRENCH, H.M., (2007). The periglacial environment. Wiley and Sons, Nueva York.

Frochoso, M., CASTAÑón, J.C., (1996). El relieve heredado de la glaciación cuaternaria en el macizo de Peña Prieta (Cordillera Cantábrica). Polígonos, 6: 25-43.

García De Celis, A., (1991). Los glaciares rocosos de la Sierra del Suspirón (León). Polígonos, 1: 9-21.

GiARdinO, J.R. SHRODER, F., VITEK, J.D., (Eds.) (1987). Rock Glaciers. Allen \& Unwin, Londres.

Gómez ORTIZ, A., (Coord.) (2002). Geomorphological Map of Sierra Nevada. Glacial and periglacial Geomorphology. Junta de Andalucía, Consejería de Medio Ambiente, Granada.

GonZÁLEZ GutiÉRrez, R.B., (2001). Estudio Geomorfológico de la montaña Central de León: Los Valles del Torío y Curueño. Tesis doctoral. Universidad de León, 426 pp., León.

GonzÁlez Trueba, J.J., (2006). La Pequeña Edad del Hielo en los Picos de Europa. Servicio de Publicaciones de la Universidad de Cantabria, Fundación Marcelino Botín, Santander.

GonzÁlez Trueba, J.J., (2007a). El paisaje natural del Macizo Central de los Picos de Europa. Centro de Investigación del Medio Ambiente (CIMA), Consejería de Medio Ambiente, Gobierno de Cantabria, Santander.

GonzÁlez TruebA, J.J., (2007b). Geomorfología del Macizo Central del Parque Nacional de Picos de Europa. O.A.P.N. Ministerio de Medio Ambiente, Madrid. 
GonzÁlez Trueba, J.J., Martin Moreno, R., Martínez De Pisón, E, Serrano, E., (2008). Little Ice Age glaciation and current glaciers in the Iberian Peninsula. The Holocene, 18 (4): 551-568.

González Trueba, J.J., Serrano, E., (2010). Geomorfología del Macizo Oriental del Parque Nacional de Picos de Europa. O.A.P.N.-Ministerio de Medio Ambiente, Madrid.

Haeberli, W., (1985). Creep of Mountain Permafrost: Internal Structure and Flow of Alpine Rock Glaciers. Mitteilungen der Versuchsanstalt für Wasserbau, Hydrology und Glaziology, Zurich.

HAmilton, S.J., Whalley, W.B., (1998). Rock glacier nomenclature: A reassessment. Geomorphology, 14: 73-80.

Harrison, S., Whalley, B., ANDERSOn, E., (2008). Relict rock glaciers and protalus lobes in the British Isles: implications for Late Pleistocene mountain geomorphology and palaeoclimate. Journal of Quaternary Science, 23: 287-304.

Humlum, O., (1998). The climatic significance of rock glaciers. Permafrost and Periglacial Processes, 9: 375-395.

JiMÉNEZ, M., (1996). El glaciarismo en la Cuenca Alta del Río Nalón (NO de España): Una propuesta de evolución de los sistemas glaciares cuaternarios en la Cordillera Cantábrica. Revista de la Sociedad Geológica de España, 9 (3-4):157-168.

JORDÁ, M., (1983). Le evolution glaciaire d'altitude dans les Alpes du Sud au cours des quinze derniers millenaires. En: Colloquium Late and Postglacial Oscillatinos of glaciers: glacial and periglacial landforms. Université de Paris, pp. 35-55, Paris.

KERSCHNER, H., (1978). Paleoclimatic inferences from Late Würm rock glaciers, eastern central Alps, western Tyrol, Austria. Arctic and Alpine Research, 10: 635-644.

KING, L., (1986). Zonation and ecology of high mountain permafrost in Scandinavia. Geografisca Annaler, 68 (A-3): 131-139.

LAMBIEL, C., ReYNARD, E., (2001). Regional modeling of present, past, and future potential distribution of discontinuous permafrost based on a rock glacier inventory in the Bagnes-Heremence area (Western Swiss Alps). Norwegian Journal of Geography, 55: 219-223.

MuÑoz, J., (1982). Geografía Física. El relieve, el clima, las aguas. Geografía de Asturias, Ayalga, Oviedo.

Pellitero, R., (2008). El Macizo del Curavacas: mapa geomorfológico e interpretación morfoestratigráfica, geoecológica y paleoclimática. Inédito, Universidad de Valladolid. 
Pellitero, R., (2009). Application of an alpine geomorphological mapping system to an Atlantic mountain environment: The Curavacas Massif (Cantabrian Range, Northwest Spain). Journal of Maps, v2009: 194-205.

Pérez Alberti, A., Martínez, A., MoARes, C., (1994). Los procesos periglaciares en el Noroeste de la Península Ibérica. En Periglaciarismo en la Península ibérica, Canarias y Baleares (Gómez A., Simón, M., Salvador, F., Eds.), Universidad de Granada, pp. 33-54, Granada.

Redondo, J.M., Carrera, P., González, B., Gómez, A., (2002). Caracterización de los macizos que dominan los glaciares rocosos fósiles de la Sierra de Gistredo (León): influencia de la fracturación en la génesis y desarrollo de las formas periglaciares. En: Periglaciarismo en montaña y altas latitudes (Serrano, E., García, A., Eds.), Dpto. Geografía de la Universidad de Valladolid, pp. 27-36, Valladolid.

REDONDO, J.M., GÓMEZ, A., GUTIÉRREZ, R.B., (2004). Localización y caracterización morfométrica de los glaciares rocosos relictos de la Sierra de Gistredo (Montaña Cantábrica, León). Cuadernos de Investigación Geográfica, 30: 35-60.

RodríGueZ, C., (1995). Estudio geomorfológico del puerto de San Isidro. Ería, 36: 63-87.

SAntos, J., Gutiérrez, R.B., Gómez Villar, A., Redondo, J.M., (2009). Ground thermal regime in the vicinity of relict rock glaciers (Cantabrian Mountains, NW Spain). Finisterra, 87: 35-44.

SERRANO, E., (1996). Líneas de equilibrio glaciar, glaciares rocosos y paleoambiente postglaciar en la alta montaña pirenaica (macizo de Panticosa, Pirineo aragonés). En: Dinámica y evolución de medios cuaternarios (Pérez Alberti, A., Martini, P., Chesworth, W., Ramil-Rego, P., Eds.), Xunta de Galicia, pp. 157-170, Santiago de Compostela.

Serrano, E., (1998). Geomorfología del Alto Gállego. Pirineo Aragonés. Institución "Fernando El Católico", Diputación de Zaragoza, Zaragoza.

Serrano, E., (2001). El relieve de Alto Campoo. En: Espacio Natural y Dinámicas Territoriales (Manero, F., Coord.), Universidad de Valladolid, pp.71-82, Valladolid.

SERrANO, E., GUTIÉRREZ, A., (2000). Las huellas de la última glaciación en Campoo. Cuadernos de Campoo, 20: 4-14.

SERrAno, E., Gutiérrez, A., (2002). El glaciarismo pleistoceno en la vertiente meridional de la Cordillera Cantábrica (montañas de Palencia, Cantabria y Burgos). Geomorfología y Paisaje. Guía de excursiones. VII Reunión Nacional de Geomorfología, Dpto. Geografía de la Universidad de Valladolid, pp.91-161, Valladolid.

Serrano, E., GonZÁlez TruebA, J.J., (2002). Morfología y evolución glaciar en los Picos de Europa. En: El modelado de origen glaciar en las montañas leonesas 
(Redondo, J.M., Gómez, A., González, R.B., Carrera, P., Eds.), Universidad de León, pp.249-268, León.

Serrano, E., Agudo, C., (2004). Glaciares rocosos y deglaciación en la alta montaña de los Pirineos aragoneses (España). Boletín de la Real Sociedad Española de Historia Natural, 99: 159-172.

Serrano, E., GonzÁlez Trueba, J.J., (2004). Morfodinámica periglaciar en el Grupo Peña Vieja (Macizo Central de los Picos de Europa -Cantabria-). Cuaternario y Geomorfología, 18 (3-4): 73-88.

Serrano, E., GonZÁlez Trueba, J.J., (2005). Assessment of geomorphosites in protected natural areas: the Picos de Europa National Park (N Spain). Geomorphologie, 3: 197-208.

SerRAT, D., (1979). Rock glacier morainic deposits in the eastern Pyrenees. En: Moraines and Varves (Schluchter, C., Ed.), A.A. Balkema, pp. 93-100. Rotterdam.

SORIA, F.J., SorIA, J.M., (1987). Depósitos de glaciares rocosos en Sierra Nevada (Granada). Acta Geológica Hispánica, 21-22: 123-129.

VilaPlanA, J.M., (1983). Quaternary Glacial Geology of Alta Ribagorza Bassin (Central Southern Pyrenees). Acta Geológica Hispánica 18(3): 235-248.

WHALLEY W.B., AZIZI F., (1994). Rheological models of active rock glaciers: evaluation, critique and a possible test. Permafrost and Periglacial Processes, 5(1): 37-51. 